\title{
HOW USEFUL ARE ESP TEXTBOOKS?
}

\author{
Ana Almagro Esteban. Universidad de Jaén
}

\begin{abstract}
The aim of this paper is to analyse the role of textbooks in English for Specific Purposes (ESP) teaching, a field where in-house materials seem to be the most appropriate option. The usefulness of textbooks often depends on their successful adaptation and our contention is that teachers do not have to be specialists in tailoring materials. In addition, textbooks are an important tool for students and this assertion is supported by the results of a questionnaire carried out in the field of Business English. The conclusion reached in this paper is that, although the perfect textbook may not exist, it is possible to settle on a compromise which suits our students' needs and at the same time reflects the teacher's view of the teaching-learning process.
\end{abstract}

\section{INTRODUCTION}

The textbook is, probably, the first choice of the teacher new to the field, expecting to cater for students' needs as well as to have a basic reference on which to base the course. In contrast, the use of in-house materials, instead of commercially published ones, seems to be the most appropriate option if we want them to fit each teaching-learning situation. In fact, if we consider the three most widely known tendencies with regard to the use of teaching materials - the use of personally tailored materials, the exclusive use of the textbook, and an intermediate position between those two (Jones, 1990) - the first is the prevailing one in the literature, since every English for Specific Purposes (ESP) course should distinguish itself by offering in-house materials (Mountford, 1988; Robinson, 1991). It is even assumed that ESP teachers' ability should be evaluated according to their capacity and experience in materials production (Swales, 1980a), ${ }^{1}$ this being one of the myths of ESP (Dudley-Evans \& St John, 1998).

Now, we find it necessary to define the aim of this paper, that is none other than analysing the usefulness of the textbook in extensive courses (taking as a reference tertiary education) and where non-immediate purposes are involved. However, we are firmly

\footnotetext{
${ }^{1}$ Cf Greehall (1984: 14) and O'Neill (1990: 155) with reference to the specific characteristics that define each learners group and how to use textbooks properly.
} 
convinced that in-house materials (conceived as those personally selected, adapted, and administered) are probably not only the best option but also the only one in other types of courses (where textbooks are just one more source of materials for the teacher, among others such as press, audio-visual materials, cassettes, etc).

Nevertheless, the production of tailored materials for every particular teaching-learning situation is not always possible on account of different circumstances that will be dealt with later. Therefore, our basic argument is that the textbook choice will be a sensible one provided that it is founded on a flexible attitude that combines its use with its adaptation to each teaching-learning situation; ${ }^{2}$ an attitude that, at the same time, is the source of authenticity in this field of English teaching: that is to say, we should be good providers of materials, which entails selecting appropriately, being creative, modifying, and supplementing (Dudley-Evans \& St John, 1998).

In this sense, Singh (1983: 157-158) forcefully endorses the need for this flexibility as well as for not feeling slaves of textbooks; agreeing with Cunningsworth (1984: 8-9), who underlines that the teacher should find the best way of adapting and using this type of material. Although the perfect textbook for each teaching-learning situation may not exist and, as a consequence, it would be pointless to expect to find it, our aim should be directed at finding the one that best corresponds to our view of the teaching-learning process and best caters for our students' needs. Grant (1987: 8-10 and 118) equally stresses that materials adaptation is an overriding criterion and, while he points out that each group of students is different, he also emphasizes the difficulty involved in teaching without a textbook, not to mention that students feel comfortable with this type of material; a point of view that is also shared by Ellis \& Johnson (1994: 117-118) and Donna (2000: 39).

Materials adaptation aside, our teaching experience in the field of General English (GE) and English for Specific Purposes has prompted us to ask why ESP textbooks do not fulfil a similar role to the one they have in teaching English for general purposes, where they are an essential tool for both teachers and students.

Swales' (1980a: 13) own words illustrate this situation: "[...] in ESP the coursebook is seen rather more as an evil, perhaps necessary at first, but to be dispensed with as soon as possible" and the question that serves as a title for Jones' (1990) article clears up the slightest doubt: "ESP textbooks: do they really exist?". Despite this fact, this author has not failed to observe that publishers' position has been similar with respect to English Language Teaching (ELT) coursebooks and ESP ones, at least as regards serialization, use of a neutral culture, and format. The only aspect that shows a different attitude in this respect is textbooks review, since in the ESP field it is frequent to launch a new product without the latter having been revised.

There is not only one reason accounting for the difficulty of finding a suitable ESP textbook: if it is important, in this sense, that each ESP course has some defining characteristics that cannot be easily transferred to a different teaching-learning situation, as well as teaching materials - so that both teachers and publishers cannot expect and claim respectively that there is an ideal textbook -; it is not less crucial that while authors' and publishers' common objective is to fill the gap in a specific field of the publishing market, the latter consider this gap in terms of the number of people that have the same needs (Greehall, 1984; Kitto, 1987). As a result, it is rather frequent to discover that ESP textbooks hide a general English course behind their title. This is why we are of the opinion that there is a straightforward connection between the high specific/intensive length of a course and the

\footnotetext{
${ }^{2}$ Cf Donna (2000: 39-40) regarding to some basic considerations we should bear in mind when adapting teaching materials to our students' needs.
}

Odisea, $n^{\circ} 2,2002$ 
almost compulsory nature of producing in-house materials, as there is a more workable possibility of using commercially published materials when we are dealing with a not so highly specific/extensive course. But a word of caution is in order here, since general and specific labels should not be confused because they are not easily reconciled in teaching English for Specific Purposes.

Nevertheless, in spite of all the drawbacks implied in the use of ESP textbooks and far from maintaining a negative attitude to their usefulness, we strongly believe these are core tools for three reasons, namely: they are the first source we can resort to when we have no time to elaborate in-house materials; teachers may not have the expertise to produce teaching materials; and, finally, ESP teaching is determined by class size (frequently very large groups), class level (normally very heterogeneous), and target needs (often quite dissimilar), factors which all make for the non-suitability of designing materials in order to match students' individual needs. Swales (1980b) and Hutchinson and Waters (1987) shed light on this matter. The former distinctly sustains that to establish a plain connection between the ESP teacher's competence and his/her ability to produce teaching materials entails the double risk of not considering existing materials that could be suitable, as well as being trapped in what he defines as the "re-invention of the wheel". In the latter-mentioned authors' opinion, the personal elaboration of teaching materials should be the last step, when commercially published materials and adaptation do not match our students' needs. ${ }^{3}$ At the same time, they clearly uphold that materials analysis is a process that helps and enriches us because it shows what to do and what to avoid.

\section{TEXTBOOKS: SERVANTS OR MASTERS?}

The review of the literature on the usefulness of textbooks allowed us to discover two articles, whose titles summarize, at first sight, two opposing views, but that turned out to be complementary in the end: "What do we want teaching materials for" (Allwright, 1981) and "Why use textbooks?" (O’Neill, 1990). If Allwright confers a very limited role on teaching materials and, similarly, on coursebooks, as a result of the complexity inherent to the language teaching-learning process, ${ }^{4}$ hence the irony implied in the title of his article; the question brought up by O'Neill's should be understood as an assertion, that is to say, as a way of justifying the advantages derived from the use of textbooks. As previously remarked, these two differing positions showed us their conciliating aspect: knowing the limitations inherent to the use of teaching materials clarifies our mediating role in the teaching-learning process, as well as the role of the textbook. Consequently, we see our task as constant scriptwriters of coursebooks, so that they are effective in each teachinglearning situation, and the role of textbooks as the main idea upon which to work out the final script. In this sense, O'Neill's (1990: 155-156) following quote is particularly eloquent: "Textbooks can at best provide only a base or a core of materials. [...] A great deal of the most important work in a class may start with the textbook but end outside it, an improvisation and adaptation, in spontaneous interaction in the class, and development from that interaction."

Likewise, our view concerning teaching materials is close to that of Praninskas (1976: 32): "A textbook is merely a prop, a body of material to be used as it is needed"; just like the

\footnotetext{
${ }^{3}$ Cf Hutchinson and Waters (1987: 125-126) because of the relevance of their remarks concerning how materials production should be conceived.

4 Cf Allwright (1980) in connection with the different reasons determining the limited usefulness textbooks can offer.
} 
position of Cunningsworth (1984: 1): "Teachers can therefore be assured that coursebooks from reputable publishers will serve them well, if properly selected and used. I used the word serve advisedly because coursebooks are good servants but poor masters"; as well as with Donna's claim (2000: 40): "Believe in yourself and use materials as a tool to enhance-not dominate!-your teaching".

Thus, the issues surrounding the role of textbooks signal a fundamental shift in teaching, a shift from the exclusive use of textbooks decades ago - where there was a dependent relationship between teachers and this type of material and where textbooks were the essence of the course - to a more flexible view regarding to their use. Greehall (1984: 14) clearly holds that this first role textbooks had has generated their own discredit, a claim that becomes obvious through the title of his article "The coursebook credibility gap". 5 However, O'Sullivan (1988: 88) also points out that textbooks are being valued more in the current and popular communicative approach.

We will now center our attention on the teaching-learning situation that is the focus of our interest, the degree of Empresariales (Business Management Studies). According to the results obtained from a questionnaire administered to the third year students of this degree (starting from a population sample of 91 students), we have to stress the following issues: the ESP textbook is the typical teaching material in this variety of English $(78,02 \%$ of students point out that an ESP coursebook was recommended in the first year of the degree we are dealing with and 95,56\% in the second one), just like in Secondary and Vocational Training Education (in which 96,70\% of students coincide in manifesting a similar circumstance). All this makes it clear that teachers are used to working with textbooks in both fields, that is to say, GE and ESP. This is probably due to their previous teaching experience in the field of English for general purposes, where the textbook is a basic tool, and also to the fact that to tailor materials is a time-consuming task, in short, to the need of resorting to an initial help that can be the leading criterion on which to base the course.

On the other hand, it follows that students value the utility of textbooks depending on whether they serve as a guide for what goes on in the classroom, an answer that, together with the rest, is semi-closed and is shown in the following graph:

\section{Graph 1. Us efulness of ESP textbooks}

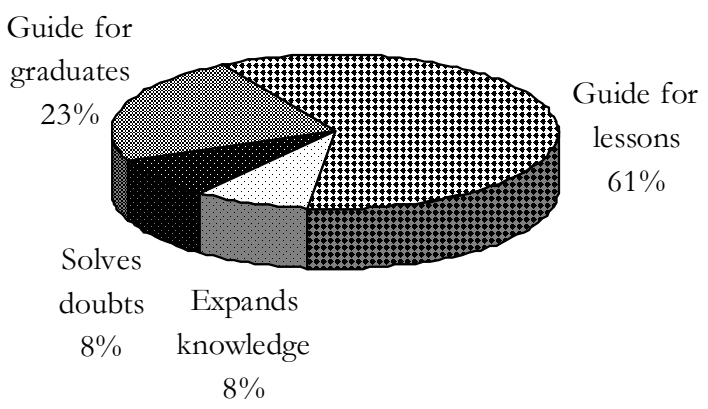

\footnotetext{
${ }^{5}$ Kitto (1987: 76) bases textbook success on the role authors, editors, and consumers have in this respect, including teachers and students in this last group, a viewpoint we pinpoint because of the relevance of this author's words as regards the term "gaps", which can refer to different aspects: "[...] topic gaps (no satisfactory book exists0 on a given topic), level gaps (no satisfactory book at a particular level), or approach gaps (no satisfactory book adopting a specific approach)". We are now in a position to clarify that it is essential that both teachers and students feel comfortable with textbooks. Thus, this is the reason why we should choose them bearing this in mind, an aspect that Kitto equally stresses (1987: 78).
}

Odisea, $n^{\circ} 2,2002$ 
Furthermore, we should stress that, although students lay emphasis on the fact that textbooks are a guide for graduates in Business Management - an option that represents 23\% -, in our opinion it is unlikely that textbooks can cater for this and, therefore, this should not be a core criterion determining coursebook selection. The latter is one of the teacher's tasks, who should complement the textbook with teaching materials from sources of all kinds (reference grammar books in accordance with students' English level, essentials for writing business correspondence [business letters, e-mails], glossaries of business correspondence, typical phrases in business correspondence, glossaries of vocabulary in a specific topic or field, etc.) in order to cater for students' learning needs, target needs, and lacks. ${ }^{6}$

As a consequence, it becomes obvious that the option solves problems represents only $8 \%$, since grammatical aspects are normally introduced from a functional approach without any type of explanation being provided for the student. In addition, grammar appendices included in textbooks deal mainly with the contents of each unit in the coursebook and, hence, they do not present an a-z of English grammar. It is also outstanding that the option expands knowledge only represents $8 \%$. This knowledge can be referred to both contents related to the students' area of specialization and to linguistic contents. It can be inferred thus that, although ESP teaching is deeply-rooted in general English, it also has its distinctive features: students expect something different because they are studying business English ${ }^{7}$ at a tertiary level and if they are specializing in the field of Social Sciences, they are also doing it in English. Therefore, ESP should offer them a new approach to teaching and learning English, that is to say, a means to prepare them for their target situation. In this sense, we should mention that, although it is not compulsory but optional that teaching materials be related to our students' field of specialization (because our aim should be to enhance their communicative competence in the four English skills), business contents and topics can provide a bridge between English teaching and the other subjects our students are engaged in, they can expand our students' knowledge of business (they are not business people yet, they are preparing for it) and, finally, they present vocabulary in an authentic way. On the other hand, as far as linguistic competence is concerned, the results obtained, although lacking statistical relevance, should lead us to think about the suitability of the entrance level of textbooks for our students' competence.

Thereby, a question arises, why not base the course on a bank of materials like the textbook, designed by experts in the field who at the same time are experts in the production of teaching materials? Beyond doubt, this is the first choice of teachers from any variety of ESP and our contention is that this will be a right option as long as we use the coursebook we recommend for our students. This will prove that our choice has been right because the textbook fulfils our expectations, that is to say, it caters for our students' needs and for our view of the teaching-learning process. Before dealing with the results obtained with regard to the lack of usefulness of ESP textbooks, we should stress that this question of the questionnaire was open-ended, in spite of which the answer unification is revealing. Naturally, if their usefulness is based on the fact that they are a guide for what goes on in the classroom, then the student ascribed their lack of utility to the fact that the textbook is not

\footnotetext{
${ }^{6}$ Cf Ellis and Johnson (1994: 117-122) due to the relevance and utility of their distinction with respect to the different types of teaching materials we can make use of (general business coursebook packages, supplementary materials, job-specific materials, reference books, and self-access materials).

${ }^{7}$ Cf Almagro (1999: 52-53) in relation to the different names we have in Spanish to refer to business English and to the reason justifying our personal option for "Inglés para los negocios" in teachinglearning situations as the one which is under scrutiny in this paper.
}

Odisea, $\mathrm{n}^{\circ} 2,2002$ 
used in lessons, an option that represents the mode with $35 \%$. These results are visually represented in the following graph:

Graph 2. Lack of usefulness of ESP textbooks
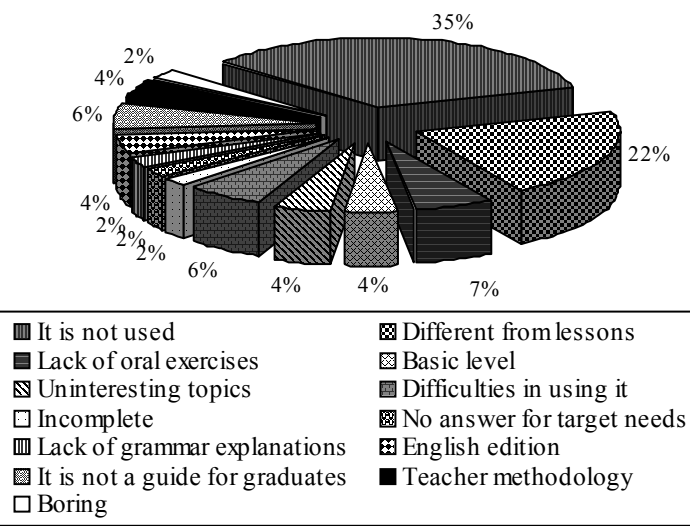

The answer option most frequently observed shows, on the one hand, that the lack of usefulness of textbooks is not only due to the coursebooks' own characteristics, but also to the use we make of them as teachers, probably because of the difficulty involved in finding a suitable one for our teaching-learning situation; and, on the other, that a textbook that can be useful for the teacher as a bank of materials, can be of no use for the student as a working tool (Cunningsworth, 1984: 65). The second answer option with relevant percentages (different from lessons with $22 \%$ ) is closely related to the fact that the textbook does not serve as a guide for what goes on in the classroom and the other options are a useful means through which to analyse the textbook drawbacks from the students'view. All this leads us to state that if we ask for our students' opinion, in this case concerning the role of textbooks, then we must take it into account.

\section{FACTORS DETERMINING TEXTBOOK SELECTION}

It is evident that textbook selection is determined by practical factors that frequently lead to a wrong choice. These are, among others, usefulness, length, methodology, level, and price (Kitto, 1987: 76). The first of them may often be the origin both of the success or failure of textbooks, because despite the fact that they have a specific aim, this may not match the use we make of them: "[...] a book which has been very well reviewed for a particular purpose does not achieve the expected level of sales simply because schools are buying it as a re-usable rather than a consumable item" (77). ${ }^{8}$ This author goes further when observing the following facts: the textbook should be useful for most of the students, its novelty is a determining factor, its length is not always appropriate for that of the course itself (although it is always an asset to have extra teaching materials), methodology is a

\footnotetext{
${ }^{8}$ Kitto (1987: 77) defines these two different uses of textbooks as follows. As regards "consumable books", he holds that: "If the book is to be kept by students, it can be highly specific to their particular needs, since one is not concerned at the time of purchase with the question of its potential re-use by other groups". However, the usefulness of non-consumable ones is completely different: "The non-consumable textbook, on the other hand, should have a repeat use value".
} 
factor hard to reconcile, the level of teaching materials must fit most of the students and, finally, the price, more often than not, determines textbook selection.

If these are aspects influencing our choice of textbooks, we, as users, should also lay down some essentials to the teaching materials publishers offer us. Mainly, they must be suitable for: 1) The non-immediate and immediate purposes in learning English (the coursebook that best fits the former situation should provide information about the area of specialization in question, whereas in the case of in-service students the focus should be not on the theoretical aspects of their field but on the enhancement of learning the language from their experience at work and the connection of teaching materials with their target situation). 2) The tasks defining our students' jobs. 3) The core English skills when carrying out these tasks. 4) The position and nationalities of our students' commercial interlocutors (very frequently these will not only be English native speakers), to mention only some aspects of interest.

\section{CONCLUSION}

We conclude by summarising the main ideas concerning the initial question of the present paper, which has been the focus of our attention, how useful are ESP textbooks? If there is a general agreement in the literature on the fact that ESP teaching should provide inhouse materials in order to cater for the distinctive features of each teaching-learning situation, it is also undeniable that the ESP textbook is a common option. Thereby, our aim has been to analyse the role of this type of teaching material at a tertiary level, that is to say, in extensive courses with non-immediate purposes, building upon the literature in the field and the results from a questionnaire carried out in the realm of teaching Business English.

We have stressed that ESP textbooks can be useful whenever we make a flexible use of them (Singh, 1983; Cunningsworth, 1984; Grant, 1987; Ellis \& Johnson, 1994; Donna, 2000), a view rather different from the one held years ago when we exclusively and abusively used textbooks: both students and teachers need something that serves as a framework, although the latter should not be slaves of textbooks. Nevertheless, this type of teaching material seems not to be as useful a tool as in the field of teaching English for general purposes (Swales, 1980a; Jones, 1990). If it is obvious that the approach of publishers has been similar in both fields, we should also bear in mind that the needs of students learning GE are homogeneous, whereas diversity is the defining criterion in teaching ESP, a factor that accounts for the credibility gap of textbooks for English for Specific Purposes.

But the task of tailoring teaching materials is a major risk if we are not experts in materials production, and this is the reason why this task should be the last step once we have checked that existing commercially published materials are useless and that adaptation has not had the expected effect. Likewise, materials analysis is a very sensible way of discovering the pros of materials as well as those aspects that require adaptation, the essence of this analysis being both asking the right questions and on-going evaluation in order to match students' needs to textbooks' proposals. On a similar note, Cunningsworth's (1984: 2) following quote is particularly eloquent: "As in most decision making, the key lies in asking the right questions and evaluating the answers".

From the students' viewpoint, the usefulness of ESP textbooks is based on the fact that they are a guide for what goes on in the classroom and, on the contrary and obvious at the same time, the lack of usefulness is stated in terms of the non-correspondence between the coursebook and the teacher's explanations. If usefulness, length, methodology, level, and price are factors deserving attention and determining textbook selection (a wrong selection in most cases); such aspects as the suitability of materials for the immediate and non- 
immediate purposes in learning English, as well as the matching process of materials to learning needs, students' lacks, and target needs are also variables influencing the effectiveness of ESP teaching. All this leads us to conclude that, although there is no one textbook that is a panacea, tailored to our students' needs, we should adapt and complement it to fit their learning and target needs.

\section{REFERENCES}

Allwright, R. L. 1980. "Abdication and responsibility in language teaching”. Studies in Second Language Acquisition 2, 1: 105-121. . 1981. "What do we want teaching materials for?”. ELT Journal 36, 1: 5-18.

Almagro, A. 1999. Análisis del Contexto Laboral y Educativo en la Enseñanza de Inglés para los Negocios y su Relevancia en la Evaluación del Libro de Texto. Tesis Doctoral. Universidad de Jaén. Edición en microfichas ISBN 84-89869-76-6.

Cunningsworth, A. 1984. Evaluating and Selecting EFL Teaching Materials. London: Heinemann.

Donna, S. 2000. Teach Business English. Cambridge: Cambridge University Press.

Dudley-Evans, T. and M. J. ST. John 1998. Developments in English for Specific Purposes. Cambridge: Cambridge University Press.

Ellis, M. and C. Johnson 1994. Teaching Business English. Oxford: Oxford University Press.

Grant, N. 1987. Making the Most of Your Textbook. London: Longman.

Greehall, S. 1984. "The coursebook credibility gap". EFL Gazette 53, 54: 14.

Hutchinson, T. and A.Waters. 1987. English for Specific Purposes: a LearningCentred Approach. Cambridge: Cambridge University Press.

Jones, G. M. 1990. "ESP textbooks: do they really exist?". English for Specific Purposes 9, 1: 89-93.

Kitto, M. 1987. "The pragmatic purchaser". ELT Textbooks and Materials: Problems in Evaluation and Development (ELT Documents 126). Ed. L. E. Sheldon. London: Modern English Publications in association with the British Council. 76-84.

Mountford, A. 1988. "Factors influencing ESP materials production and use". ESP in the Classroom: Practice and Evaluation (ELT Documents 128). Eds. D. Chamberlain and R. J. Baumgardner. London: Modern English Publications in Association with the British Council. 76-84.

O’Neill, R. 1990. "Why use textbooks?”. Currents of Change in English Language Teaching. Eds. R. Rossner and R. Bolitho. Oxford: Oxford University Press.148-156.

O'Sullivan, T. 1988. "Coursebook evaluation: focus on motivation and learning”. Modern Languages 69, 2: 88-91.

Praninskas, J. 1976. "The teacher and the textbook". English Teaching Forum 14, 4: 3033. 
Robinson, P. C. 1991. ESP Today: A Practitioner's Guide. New York: Prentice Hall.

Singh, R. K. 1983. "ESP: communication constraints”. System 11, 2: 155-158.

Swales, J. 1980a. "ESP: the textbook problem". The ESP Journal 1, 1: 11-23.

. 1980b. "The educational environment and its relevance to ESP programme design". Projects in Material Design. ELT Documents Special. London: ETIC Publications, The British Council. 61-70. 